\title{
Prevalência de lesões em atletas amadores de corrida de rua
}

\section{André Jaime de Oliveira Alves}

Pós Graduando em Educação Física Escolar pelo Centro Universitário Internacional e Licenciado em Educação Física pelo Centro Universitário de Barra Mansa. E-mail: and-bm@hotmail.com.

\section{Glauco Fonseca de Oliveira}

Mestre em Geriatria Clínica e Social pela Universidade Europeia Miguel de Cervantes e Docente do Curso de licenciatura em Educação Física do Centro Universitário de Barra Mansa. E-mail: glauco.oliveira1975@icloud.com. 


\section{Resumo}

A corrida de rua está entre as modalidades mais praticadas no mundo, e o número de adeptos cresce a cada ano. Isso se deve aos benefícios que a atividade proporciona e o baixo custo. Como consequência, temos um aumento no número de lesões sofridas pelos praticantes. A partir desse cenário, este artigo, de revisão bibliográfica, tem como objetivo analisar a prevalência de lesões em atletas amadores de corrida de rua e citar suas causas. Foram realizadas buscas em diferentes bancos de dados para identificar artigos científicos a fim de concretizar os objetivos. Foi possível concluir que as lesões em atletas amadores podem ser atribuídas a diferentes fatores, tais como: treinos em excesso e nutrição inadequada. Dentre as lesões mais prevalentes, a região do joelho é destacada pela literatura como a mais afetada.

Palavras-chave: Prevalência de lesões. Atletas amadores. Corrida de rua.

\section{Abstract}

The street racing is among the methods most widely practised in the world and the number of supporters grows every year. This is due to the benefits that the activity offers and low cost. As a result, we have an increase in the number of injuries sustained by the practitioners. From this scenario, this article, review, aims to analyze the prevalence of injuries in amateur athletes of street racing and cite its causes. Searches were held in different databases to identify scientific articles in order to achieve the goals. It was possible to conclude that the injuries in amateur athletes can be attributed to different factors, such as: lots of trainings and inadequate nutrition. One of the most prevalent injuries, knee region is highlighted by the literature as the most affected.

Keywords: Prevalence of injuries. Amateur athletes. Street racing. 


\section{Introdução}

Atualmente, a prática de atividades físicas está se tornando mais expressiva, isso se deve aos benefícios que é capaz de promover. Entre as diversas atividades esportivas, as corridas de rua estão entre as que mais crescem nos últimos anos. Fatores como: baixo custo para treinamento, organização e participação contribuíram para o crescimento dessa atividade (SALGADO; MIKAHIL, 2006).

As corridas de rua surgiram na Inglaterra no século XVII, se tornaram populares e acabaram se expandido para o resto da Europa e Estados Unidos. No fim do século $\mathrm{XIX}$, impulsionadas pelo sucesso da primeira maratona olímpica, as corridas de rua ganharam maior notoriedade nos Estados Unidos (SALGADO; MIKAHIL, 2006).

Conforme critérios da Federação Internacional das Associações de Atletismo (IAAF), as corridas de rua são provas disputadas em ruas pavimentadas e com distâncias variadas, podendo chegar a $100 \mathrm{~km}$ (CONFEDERAÇÃO BRASILEIRA DE ATLETISMO, 2014).

Apesar de todos os benefícios apresentados pelos praticantes de corrida de rua, observa-se uma elevada incidência de lesões no aparelho locomotor, principalmente nos membros inferiores (PILEGGI et al., 2010).

As lesões em diferentes esportes são decorrentes a diversos fatores que podem ser divididos em extrínsecos e intrínsecos. Os fatores extrínsecos são direta ou indiretamente ligados à preparação ou à prática da corrida de rua e envolvem erros de planejamento e execução durante o treinamento. Já os fatores intrínsecos são inerentes ao organismo e incluem anormalidades biomecânicas e anatômicas, flexibilidade, histórico de lesões, características antropométricas, densidade óssea, composição corpórea e condicionamento cardiovascular (FERREIRA et al., 2012).

$\mathrm{O}$ número de adeptos às corridas de rua vem crescendo significativamente nos últimos anos devido aos benefícios que a mesma proporciona. Porém, mesmo com todos os benefícios, se praticada de modo incorreto, pode ocasionar lesões. Sendo assim, esta revisão bibliográfica tem o objetivo de analisar, por meio de artigos e literaturas específicas, a prevalência de lesões em atletas amadores e citar suas causas. 


\section{O atleta amador nas corridas de rua}

A corrida de rua é uma prática cultural e cada vez mais se desenvolve nos principais centros urbanos do mundo. Considerado o exercício físico mais comum e mais praticado; a corrida está associada à promoção de um estado de euforia, em seus praticantes, e ao prazer em competir e vencer. A busca pela qualidade de vida é um dos maiores atrativos oferecido pela corrida de rua atualmente. Isso porque correr na rua não é somente um exercício físico, trata-se do ser humano em ação, o que compreende a relação entre corpo e movimento no contexto sociocultural. A corrida de rua passou a integrar a agenda de pessoas de várias idades, padrões econômicos, socioculturais e profissões distintas, seja por questões relacionadas à saúde, lazer, estética ou até mesmo ao desempenho esportivo. (AUGUSTI et al., 2011)

A maioria dos praticantes de corrida de rua são amadores que buscam melhorar a qualidade de vida, aliando treinamentos constantes e hábitos saudáveis. (SILVA; SOUSA, 2013) O atleta amador é a pessoa que se dedica ao desporto por lazer, não recebendo nenhuma espécie de remuneração ou retribuição, seja direta ou indiretamente. É um praticante eventual, que o faz por saúde, prazer ou vaidade. O amador segue o ideal proposto por Pierre de Coubertin, que consiste no fato de que o importante não é vencer e sim participar. (KRIEGER, 2003)

A corrida de rua é vista como um esporte para todos, pois pode ser praticada por atletas amadores e profissionais com diferentes níveis de condição física. Nas provas oficiais, os atletas amadores e os profissionais dividem o mesmo espaço. É comum ver milhares de anônimos correndo ao lado dos seus ídolos, algo que não acontece em esportes como o futebol ou basquete. (MARQUES; DOS SANTOS, 2016)

\section{Lesões em corredores de rua}

A atividade física tem sido recomendada cada vez mais, principalmente no combate ao sedentarismo. No entanto, se realizada em grande intensidade, pode ocasionar lesões. $\mathrm{O}$ aumento da velocidade e intensidade na corrida de rua levam a uma maior força contra o solo, a qual é transmitida para a estrutura funcional do corredor 
(ligamentos, músculos, ossos e tendões), podendo então ocasionar lesões com o passar do tempo. (DE SOUZA et al., 2013)

As lesões que normalmente ocorrem durante as corridas não são iguais as do futebol ou do esqui. Metade dos corredores sofre lesões durante todo o ano, mas na maioria das vezes não há necessidade de ficar engessado ou se afastar dos treinos por um longo período. Muitas lesões de corrida não são perceptíveis ao andar ou ao fazer outras atividades corriqueiras, elas só são notadas quando começamos a correr. $\mathrm{Na}$ corrida, as lesões se originam por vários fatores, entre eles estão a maneira como o corpo se adapta ao desgaste, ao peso de cada pisada e a força muscular necessária para colocar um pé após o outro. (BARRIOS, 2009)

Muitos atletas têm a tendência de realizar treinos por conta própria, sem orientação adequada de um profissional de Educação Física, em função desse fato correm o risco de adquirir lesões com maior facilidade. Existem atletas que treinam sem orientações e não se lesionam, no entanto, sem o acompanhamento necessário, aumentam os riscos de lesões crônicas, tornando difícil a recuperação e gerando afastando dos treinos e competições. (FONSECA, 2012)

Em Estudo realizado com 100 atletas amadores no município de Belo Horizonte/MG, 40\% dos entrevistados relataram lesões nos últimos seis meses. A variação no volume do treinamento e a distância média diária se destacavam entre os fatores associados às lesões. (FERREIRA et al., 2012)

\section{Metodologia}

Foi realizada uma revisão bibliográfica com o objetivo de descrever e compreender a prevalência de lesões em atletas amadores de corrida de rua. Para o levantamento bibliográfico, optou-se por artigos nacionais e internacionais, no período de 2003 a 2016, sendo considerados apenas as pesquisas transversais (ou de prevalência), disponíveis nas bases de dados da Biblioteca Virtual em Saúde (BIREME), Scientific Electronic Library Online (SCIELO) e Google Acadêmico. Os descritores utilizados foram: "Corrida de Rua", "Lesões em Corredores" e "Prevalência de Lesões em Corredores". 


\section{Discussão}

Conforme Souza e Floret (2012), a falta de experiência e a má orientação levam a uma sobrecarga nos treinamentos, causando lesões e dificultando a melhora no desempenho do atleta. A nutrição é outro fator que pode influenciar nas lesões. Os praticantes de corrida de rua, na maioria das vezes, apresentam o consumo de macronutrientes abaixo do recomendado. A corrida exige grande esforço físico e causa desgaste ao organismo. Sendo assim, uma dieta pobre em carboidrato pode afetar a massa muscular, baixar a reserva de glicogênio nos músculos e aumentar a fadiga, comprometendo o desempenho do corredor e ocasionando lesões. Ao realizarem uma pesquisa com 77 atletas amadores de corrida de rua (34 mulheres e 43 homens), comprovaram que 32,5\% dos participantes sofreram algum tipo de lesão nos últimos 12 meses e que a região do corpo mais afetada foi o joelho, atingindo 14,3\% dos pesquisados.

Hespanhol Junior et al. (2012), ao realizarem um estudo com 200 corredores, constataram que a prevalência de lesões musculoesqueléticas relacionadas à corrida de rua foi de 55\% nos últimos 12 meses, tendo como principais diagnósticos as tendinopatias $(17,3 \%)$ e as lesões musculares $(15,5 \%)$. A região anatômica mais afetada foi o joelho com 27,3\%. Com isso, sugerem que sejam realizados estudos para acompanhar e averiguar os fatores que influenciam o surgimento de novas lesões musculoesqueléticas relacionadas à corrida de rua.

Campos et al. (2016), investigaram 139 atletas amadores e os resultados mostraram que 37\% já apresentaram lesões, enquanto $63 \%$ não apresentaram. A frequência de lesões em corredores com menos de um ano de prática foi de 79,6\%. Tendo como prevalência as tendinites e canelites. Entre os investigados, o joelho e a face anterior da perna se destacaram como as regiões mais afetadas por lesões.

Cury (2015), em estudo transversal descritivo, realizado com 32 atletas amadores, sendo 22 homens e 10 mulheres, verificou que 68,75\% dos avaliados sofreram alguma lesão associada à corrida de rua. Entre as lesões com maior incidência estavam as inflamações no joelho (61,5\%), tendinites no tendão de Aquiles e estiramentos na coxa $(15,4 \%)$ e canelites $(7,7 \%)$.

Rangel e de Farias (2016), realizaram um estudo descritivo transversal com 88 corredores (56 homens e 32 mulheres), observando-se que 43,2\% dos analisados haviam 
sofrido alguma lesão. Sendo o joelho o local mais acometido, atingindo 52,6\% dos corredores. Entre os que haviam sofrido algum tipo de lesão, houve forte correlação entre a quantidade de lesões, o tempo de prática da modalidade e a maior distância média diária percorrida durante os treinos.

Fernandes et al. (2014), ao estudarem 107 corredores de longa distância (85 homens e 22 mulheres), encontraram maiores ocorrências de lesões na articulação do joelho (27\%), seguida por lesões no tornozelo (17\%), panturrilha (13\%) e perna (13\%). O pé mostrou incidência de $9 \%$, seguido do tendão de Aquiles com $4 \%$ e as demais regiões anatômicas somando $16 \%$. Os dados para a pesquisa foram obtidos durante o registro dos atletas na Maratona Internacional de São Paulo e Meia Maratona de Campinas.

Purim et al. (2014), através de estudo transversal com 220 atletas de corrida de rua, verificaram que as principais lesões relatadas foram dor no joelho (30,4\%), distensão/estiramento muscular (16,7\%), tendinites $(10,1 \%)$, dor nos quadris $(7,3 \%)$ e dor na coluna (7\%). Os resultados foram obtidos por meio de observação clínica e preenchimento de questionário, predominando os corredores do sexo masculino; praticantes de corrida de longa distância; adultos, que treinam em média 45 a 60 minutos por dia, com frequência de duas a três vezes por semana.

Para Yamato et al. (2011), são necessários mais estudos e pesquisas sobre o assunto, uma vez que, mais de um quarto da população de corredores participam das provas de corrida sentindo algum tipo de dor.

\section{Conclusão}

A corrida de rua é capaz de proporcionar bem-estar físico e mental aos seus praticantes. Mas, como toda atividade física, deve ser realizada de forma moderada e seguir algumas regras. Antes de iniciar na modalidade, o futuro corredor deverá passar por uma avaliação médica, física e nutricional. Dessa forma, descobrirá os limites do próprio corpo e poderá prevenir lesões.

Observam-se diversos fatores que podem ocasionar lesões em corredores amadores. Entre eles estão, a falta de acompanhamento profissional, treinamentos realizados em excesso ou de forma incorreta e a nutrição inadequada. As pesquisas 
citadas apontam variações na prevalência de lesões e citam o joelho como a região anatômica mais afetada.

Diante dos fatos, sugere-se a elaboração de novos estudos e pesquisas sobre as lesões que afetam os atletas amadores de corrida de rua, suas possíveis causas e formas de prevenção. Auxiliando para que a modalidade seja praticada de forma correta e segura.

\section{Referências}

AUGUSTI, M.: Corrida de rua e sociabilidade. EFDeportes.com Revista Digital. Buenos Aires, ano 16, n. 159, Agosto de 2011. Disponível em: $<$ http://www.efdeportes.com/efd159/corrida-de-rua-e-sociabilidade.htm>. Acesso em: 25 Set. 2015.

BARRIOS, D. S. Guia de prevenção e tratamento de dores e lesões. São Paulo: Gente, 2009. $193 \mathrm{p}$.

CAMPOS, A.C. et. al. Prevalência de lesões em corredores de rua amadores. Revista Brasileira de Pesquisa em Ciências da Saúde. Brasília, v. 3, n. 1, 2016. Disponível em: <http://www.icesp.br/revistas-eletronicas/index.php/RBPeCS/article/view/64/66>. Acesso em: 24 Jul. 2017.

CONFEDERAÇÃO BRASILEIRA DE ATLETISMO. Regras oficiais da IAAF que tratam de corridas. Ed. Oficial. Brasil, 2014. Disponível em:

<http://www.cbat.org.br/normas/Regras_IAAF_de_Corridas.pdf>. Acesso em: 11 Set. 2015 .

CURY, M. Lesões com maiores incidência em corredores de rua amadores da cidade de Bauru, SP. EFDeportes.com Revista Digital. Buenos Aires, Ano 19, n. 202, Março de 2015. Disponível em: <http://www.efdeportes.com/efd202/lesoes-em-corredores-derua-amadores.htm>. Acesso em: 24 Jul. 2017.

DE SOUZA, C. A. B. et. al. Principais lesões em corredores de rua. Revista UNILUS Ensino e Pesquisa. São Paulo, v. 10, n. 20, Jul/set. 2013. Disponível em: <http://revista.lusiada.br/index.php/ruep/article/view/103>. Acesso em: 28 Out. 2015.

FERNANDES D. et. al. Fatores de risco para lesões em corredores de rua amadores do estado de São Paulo. Revista Brasileira de Prescrição e Fisiologia do Exercício. São Paulo, v. 
8, n. 49, Set/Out. 2014. Disponível em:

<http://www.rbpfex.com.br/index.php/rbpfex/article/view/674/639>. Acesso em: 24 Jul. 2017.

FERREIRA, A. C. et. al. Prevalência e fatores associados a lesões em corredores amadores de rua do município de Belo Horizonte, MG. Revista Brasileira de Medicina do Esporte. São Paulo, v. 28, n. 14, Jul/ago. 2012. Disponível em: <http://www.scielo.br/pdf/rbme/v18n4/v18n4a07>. Acesso em: 11 Set. 2015.

FONSECA, T. Z. Corrida de rua: o aumento do número de praticantes migrando para maratonas. EFDeportes.com Revista Digital. Buenos Aires, Ano 16, n. 164, Janeiro de 2012. Disponível em: <http://www.efdeportes.com/efd164/corrida-de-rua-o-aumentodo-numero-de-praticantes.htm>. Acesso em: 24 Jul. 2017.

HESPANHOL JUNIOR, L. C. et. al. Perfil das características do treinamento e associação com lesões musculoesqueléticas prévias em corredores recreacionais: um estudo transversal. Revista Brasileira de Fisioterapia. São Carlos, v. 16, n. 1, Jan/fev. 2012. Disponível em: <http://www.scielo.br/pdf/rbfis/v16n1/09.pdf>. Acesso em: 28 Out. 2015.

KRIEGER, M. Disposições relativas ao atleta no direito desportivo brasileiro. Revista Brasileira de Direito Desportivo. São Paulo, v. 3, 2003.

MARQUES, J. C.; DOS SANTOS, M. C. Corrida de rua e representação social: análise da campanha publicitária "it's runderful" da mizuno. Revista de Gestão e Negócios do Esporte. São Paulo, v. 1, n. 2, Nov. 2016. Disponível em: <http://revistagestaodoesporte.com.br/pluginfile.php/342/mod_resource/content/1/6_C orrida\%20de\%20Rua\%20e\%20Representacao\%20Social\%20Analise\%20da\%20Campan ha\%20Publicitaria\%20Its\%20Runderful\%20da\%20Mizuno\%20.pdf>. Acesso em: 24 Jul. 2017.

PILEGGI, P. Incidência e fatores de risco de lesões osteomioarticulares em corredores: um estudo de coorte prospectivo. Revista Brasileira de Educação Física e Esporte. São Paulo, v. 24, n. 4, Out/dez. 2010. Disponível em: <http://www.scielo.br/pdf/rbefe/v24n4/a03v24n4.pdf>. Acesso em: 11 Set. 2015.

PURIM, K. S. M. et. al. Lesões desportivas e cutâneas em adeptos de corrida de rua. Revista Brasileira de Medicina do Esporte. São Paulo, v. 20, n. 4, Jul/Ago. 2014. 
Disponível em: <http://www.scielo.br/pdf/rbme/v20n4/1517-8692-rbme-20-0400299.pdf>. Acesso em: 24 Jul. 2017.

RANGEL, G. M.; DE FARIAS. J. M. Incidência de lesões em praticantes de corrida de rua no município de Criciúma, Brasil. Revista Brasileira de Medicina do Esporte. São Paulo, v. 22, n. 6, Nov/Dez 2016. Disponível em: < http://www.scielo.br/pdf/rbme/v22n6/1517-8692-rbme-22-06-00496.pdf>. Acesso em: 24 Jul. 2017.

SALGADO, J. V. V.; MIKAHIL, M. P. T. C. Corrida de rua: análise do crescimento do número de provas e de praticantes. Revista da Faculdade de Educação Física da UNICAMP. Campinas, v. 4, n. 1, 2006. Disponível em: <http://fefnet178.fef.unicamp.br/ojs/index.php/fef/article/view/57/39>. Acesso em: 11 Set. 2015.

SILVA, M. S.; SOUSA, M. S. O papel das assessorias esportivas no crescimento das corridas de rua no Brasil. Revista Científica da Federação Internacional de Educação Física. Paraná, v. 83, 2013. Disponível em:

<http://www.fiepbulletin.net/index.php/fiepbulletin/article/viewFile/2952/5756>. Acesso em: 24 Jul. 2017.

SOUZA, I. S.; FLORET, M. Prevalência de lesões e tipo de treinamento de atletas amadores de corrida de rua. Corpus et Scientia - Revista da UNISUAM. Rio de Janeiro, v.8, n. 1, Jun. 2012. Disponível em:

<http://apl.unisuam.edu.br/revistas/index.php/corpusetscientia/article/view/7/12>. Acesso em: 28 Out. 2015.

YAMATO, T. P. et. al. Prevalência de dor musculoesquelética em corredores de rua no momento em que precede o início da corrida. Revista Brasileira de Ciências do Esporte. Florianópolis, v. 33, n 2, Abri/jun. 2011. Disponível em: <http://www.scielo.br/pdf/rbce/v33n2/13.pdf>. Acesso em: 28 Out. 2015. 